\title{
PERANCANGAN E-SKRIPSI UNIVERSITAS MUHAMMADIYAH BENGKULU MENGGUNAKAN USER CENTERED DESIGN (UCD)
}

\section{DESIGN OF THE MUHAMMADIYAH UNIVERSITY OF BENGKULU E- SCRIPTION USING USER CENTERED DESIGN (UCD)}

\author{
Marissa Utami $^{1}$, Yovi Apridiansyah ${ }^{2}$, Erwin Dwika Putra ${ }^{3 *}$ \\ ${ }^{1}$ Sistem Informasi, Fakultas Teknik, Universitas Muhammadiyah Bengkulu, \\ ${ }^{2,3}$ Teknik Informatika, Fakultas Teknik, Universitas Muhammadiyah Bengkulu \\ *erwindwikap@gmail.com
}

\begin{abstract}
Considering the importance of thesis guidance for students in solving problems and developments in the world of education that allow remote teaching and guidance, it can be concluded that a forum is needed to facilitate the process of student thesis guidance for supervisors, with the development of online-based information system technology today, this too is one of the reasons for the need for a thesis guidance information system development. In line with the current implementation of the health protocol against the Covid-19 pandemic from the Ministry of Education and culture, and considering the importance of developing long-distance guidance, this research will develop a remote guidance information system that aims to facilitate the student thesis guidance process. In system development, the User Centered Design approach method is used which involves the user in every stage of system development, so that the system formed can be used appropriately according to the wishes of the system user.
\end{abstract}

Keywords: User, E-Skripsi, Covid-19, UCD.

\begin{abstract}
ABSTRAK
Mengingat pentingnya bimbingan skripsi bagi mahasiswa dalam menyelesaikan masalah dan perkembangan dalam dunia pendidikan yang memungkinkan pengajaran maupun bimbingan jarak jauh maka dapat disimpulkan dibutuhkannya suatu wadah untuk memudahkan proses bimbingan skripsi mahasiswa terhadap dosen pembimbing, dengan berkembangnya teknologi sistem informasi berbasis online saat ini, hal ini pun menjadi salah satu alasan diperlukannya pengembangan sistem informasi bimbingan skripsi. Sejalan dengan saat ini diterapkannya protocol kesehatan terhadap pandemi Covid-19 dari Kementrian Pendidikan dan kebudayaan, serta mengingat pentingnya pengembangan bimbingan jarak jauh, maka pada penelitian ini akan dikembangkan sebuah sistem informasi bimbingan jarak jauh yang bertujuan untuk memudahkan proses pembimbingan skripsi mahasiswa. Dalam pengembangan sistem digunakan metode pendekatan User Centered Design yang mengikutsertakan pengguna dalam setiap tahapan pengembangan sistem, sehingga sistem yang dibentuk dapat digunakan secara tepat sesuai dengan keinginan pengguna sistem.
\end{abstract}

Kata Kunci: Pengguna, E-Skripsi, Covid-19, UCD.

\section{PENDAHULUAN}

Bimbingan skripsi atau tugas akhir merupakan hal yang wajib dilakukan antara Dosen dan Mahasiswa untuk mencapai hasil pencapaian skripsi yang sesuai dengan harapan pada penelitian skripsi tersebut(Muhammad, 2014).

Mengingat pentingnya bimbingan skripsi bagi mahasiswa serta dalam menyelesaikan masalah dan perkembangan dalam dunia Pendidikan yang memungkinkan pengajaran maupun bimbingan jarak jauh maka dapat disimpulkan dibutuhkannya suatu wadah untuk memudahkan proses bimbingan skripsi mahasiswa terhadap dosen pembimbing(Utari \& Hercules, 2017; Dwiyani, 2013) dengan berkembangnya teknologi sistem informasi berbasis online saat ini, hal ini pun menjadi salah satu alas an diperlukannya pengembangan system 
informasi bimbingan skripsi (Yesputra \& Marpaung, 2018; Patimah \& Samsudin, 2018).

Pada saat ini proses pembimbingan skripsi masih menggunakan sistem tatap muka, dimana mahasiswa wajib menemui dan membuat janji kepada dosen pembimbing skripsi, proses ini mempunyai kelemahan yaitu availability time schedule, dimana mahasiswa dan dosen susah untuk menentukan jadwal pertemuan bimbingan skripsi.

Sejalan dengan saat ini diterapkannya protokol Kesehatan terhadap pandemi Covid-19 dari Kementrian Pendidikan dan Kebudayaan, serta mengingat pentingnya pengembangan bimbingan jarak jauh, maka pada penelitian ini akan dikembangkan sebuah sistem informasi bimbingan jarak jauh yang bertujuan untuk memudahkan proses pembimbingan skripsi mahasiswa.

Penelitian yang telah dikembangkan sebelumnya oleh melda agnes manuhutu dengan judul penelitian "Perancangan Siste Informasi Konsultasi Akademik Berbasis Website" disimpulkan bahwa system informasi yang dikembangkan sangatlah sepnting dan bermanfaat bagi mahasiswa(Yesputra \& Marpaung, 2018).

Dalam proses bimbingan akademik juga telah dikembangkan oleh faiza rini dengan judul penelitian "Bimbingan Skripsi Online Berbasis Web Pada Program Studi Sistem Informasi STMIK Nurdin Hamzah" dimana pada penelitian ini menghasilkan Website yang memudahkan mahasiswa dalam berkonsultasi masalah skripsi, akan tetapi masih belum dapat memberikan ajuan seperti judul dan berkas yang akan di upload hanya sebatas diskusi secara akademik kepada pembimbing(Rini \& Purnama, 2019).

Konsultasi akademik merupakan layanan untuk membantu siswa maupun mahasiswa dalam mendapatkan sebuah pemahaman serta menemukan solusi sebuah masalah yang dihadapi. Bimbingan skripsi juga termasuk dalam konsultasi akademik dimana pada skripsi dibutuhkan satu sampai dua orang penasehat (pembimbing) untuk mahasiswa berbagi dan berdiskusi dalam memecahkan sebuah masalah(Lena, 2021).

Penelitian ini menggunakan pendekatan User Centered Design merupakan metode pengembangan sistem yang mengutamakan pada kebutuhan pengguna sehingga sistem yang dikembangkan menjadi solusi yang tepat bagi masalah yang dihadapi pengguna(Ali, 2016).

Sistem yang dihasilkan akan melalui proses uji fungsionalitas(Febriansari \& Atmojo, 2021), yaitu pengujian kepada seluruh fitur yang ada pada sistem agar mendapatkan hasil uji berupa validitas fitur bekerja dengan baik atau tidak menggunakan Black Box Testing(Sari, 2021).

\section{METODE}

Penelitian ini melalui empat tahapan yang ada pada pendekatan User Centered Design (UCD) yaitu Plan, Design, Prototype dan Review(Ramadhan, 2021; Sidabuta, et. al., 2021).



Gambar 1. Tahapan Penelitian

Pada tahapan Plan dimulai dari pengumpulan data untuk menginisisasi kebutuhan pengguna untuk memastikan 
sistem yang dikembangkan nantinya sesuai dengan kebutuhan dari pengguna itu sendiri. Dilanjutkan pada tahapan Design, proses menganalisis data yang didapatkan lalu hasil analisis yang didapatkan digunakan untuk merepresentasikan bagaimana sistem berjalan menggunakan Unified Modelling Languange(Putra \& Gunawan, 2021; Vani, et. al., 2021). Pada tahapan Prototype visual alur sistem yang dihasilkan dari tahapan Design di implementasikan menjadi sebuah sistem yang utuh. Prototype yang dihasilkan lalu diuji fungsionalitas oleh pengguna pada tahapan Review.

\section{HASIL DAN PEMBAHASAN}

Pada tahapan Plan, didapatkan empat kebutuhan dasar dari pengguna yaitu Fitur Login, Fitur Upload File, Fitur Catatan Pembimbing dan Fitur Lembar Persetujuan Pembimbing.

Tabel 1. Kebutuhan Dasar Pengguna

\begin{tabular}{|c|c|c|}
\hline No & Nama Fitur & Keterangan \\
\hline 1 & Login & $\begin{array}{lr}\text { Pada fitur login } \\
\text { terdapat } 3 \text { bagian } \\
\text { yaitu } & \text { Login } \\
\text { sebagai } & \\
\text { Mahasiswa, Login } \\
\text { sebagai } \\
\text { Pembimbing dan } \\
\text { Login sebagai } \\
\text { Ketua Program } \\
\text { Studi }\end{array}$ \\
\hline 2 & Upload File & $\begin{array}{l}\text { Pada fitur ini } \\
\text { mahasiswa dapat } \\
\text { mengirimkan } \\
\text { naskah skripsi } \\
\text { untuk direview } \\
\text { oleh dosen } \\
\text { pembimbing }\end{array}$ \\
\hline 3 & $\begin{array}{l}\text { Catatan } \\
\text { Pembimbing }\end{array}$ & $\begin{array}{l}\text { Pada fitur ini } \\
\text { dosen } \\
\text { pembimbing } \\
\text { dapat } \\
\text { mengirimkan } \\
\text { hasil review dari } \\
\text { naskah skripsi } \\
\text { yang dikirikan } \\
\text { oleh mahasiswa } \\
\text { yang dapat juga }\end{array}$ \\
\hline
\end{tabular}



Pada Tahapan Design, didapatkan alur hubungan antara objek dengan sistem dimana objek yang dimaksud adalah Mahasiswa, Dosen Pembimbing dan Ketua Program Studi.

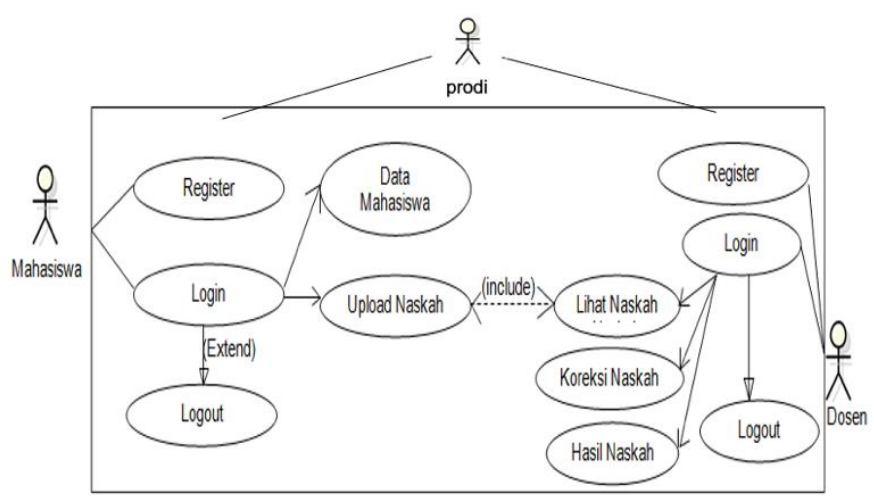

Gambar 2. Alur Keterhubungan objek dan Sistem

Selain alur hubungan objek dengan sistem, didapatkan pula gambaran interaksi antara objek satu dengan yang lainnya didalam sistem serta proses apa saja yang ada dalam sistem.

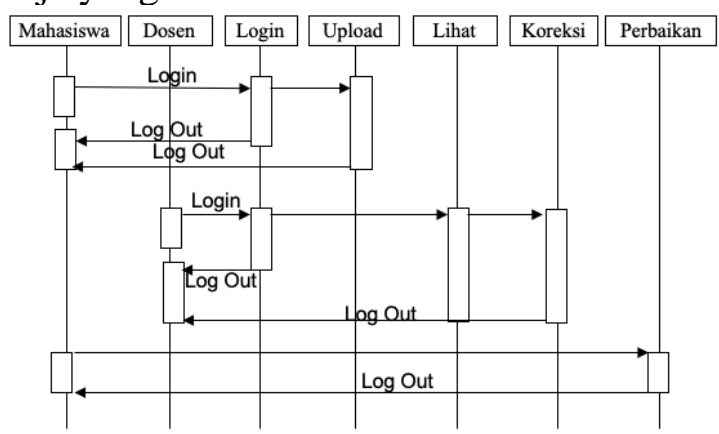

Gambar 3. Proses Interaksi dalam Sistem 
Pada tahapan Prototype, dibuat sebuah desain awal sistem yang menggambarkan 4 fitur yang diinginkan oleh pengguna lalu direview untuk didapatkan hasil validasi sistem.

\section{SIMPULAN}

Telah dilakukan 4 tahapan pada UCD hingga menghasilkan 4 kebutuhan dasar pengguna dalam sistem yang dibangun. Berdasarkan pengujian yang dilakukan dengan menggunakan Blackbox Testing dihasilkan rata-rata penilaian sebesar $65,50 \%$. Hasil ini menunjukkan bahwa sistem yang dihasilkan sudah dianggap valid.

\section{DAFTAR PUSTAKA}

Ali, E. (2016). Metode User Centered Design (UCD) dalam Membangun Aplikasi Layanan Manajerial di Perguruan Tinggi. Sains dan Teknologi Informasi, 2(2), 1-6.

Dwiyani, A. (2013). Perancangan Sistem Pendukung Bimbingan Online Tugas Akhir Mahasiswa Program Studi Teknik Informatika. JUSTIN (Jurnal Sistem dan Teknologi Informasi), 1(3), 171175.

Febriansari, D., \& Atmojo, I. R. W. (2021). NgaBatik: Aplikasi Pengenalan Motif Batik Ngawi Berbasis Android. Syntax Literate; Jurnal Ilmiah Indonesia, 6(2), 620-636.

Lena, S. (2021). Perancangan Dan Implementasi Sistem Manajemen Proposal Skripsi (Studi Kasus Jurusan Manajemen Informatika Politeknik Negeri Sambas). KlikKumpulan Jurnal Ilmu Komputer, 8(1), 73-83.

Manuhutu, M. A., \& Wattimena, J. (2019). Perancangan Sistem Informasi Konsultasi Akademik
Berbasis Website. Jurnal Sistem

Informasi Bisnis, 9(2), 25022377.

Muhamad, W. (2014). Aplikasi bimbingan tugas akhir online. Jurnal Teknologi Informasi, 1(7), 245-252.

Ramadhan, S. L. (2021). Perancangan User Experience Aplikasi Pengajuan E-KTP menggunakan Metode UCD pada Kelurahan Tanah Baru. JATISI (Jurnal Teknik Informatika dan Sistem Informasi), 8(1), 287-298.

Rini, F., \& Purnama, F. (2019, November). Bimbingan Skripsi Online berbasis Web Pada Program Studi Sistem Informasi STMIK Nurdin Hamzah. In SEMINAR NASIONAL APTIKOM (SEMNASTIK) 2019 (pp. 520527).

Sari, N. R. (2021). Sistem Informasi Pengolahan Nilai Siswa Di SD Al-Hidayah Tangerang. PROSISKO: Jurnal Pengembangan Riset dan Observasi Sistem Komputer, 8(1), 68-74.

Sidabutar, J. C., Rajagukguk, E., Naibaho, J. F., Hasibuan, D., \& Hasibuan, J. M. (2021). Penerapan Marketplace Penjualan Cinderamata Khas Batak Di Destinasi Wisata Kabupaten Samosir Berbasis Android. Jurnal Ilmiah Sistem Informasi METHOSISFO, 1(1), 20-26.

Utariani, U., \& Herkules, H. (2017). Monitoring Bimbingan Skripsi Online Pada Sekolah Tinggi Manajemen Informatika dan Komputer (STMIK) Palangka Raya. Jurnal Saintekom, 7(1), 3347.

Patimah, S., \& Samsudin, B. R. (2018). Aplikasi Manajemen E-Skripsi Online (Studi Kasus Prodi Sistem 
Informasi Universitas Islam Indragiri). Jurnal Sistemasi, 7(3), 98-103.

Putra, I. M. A. W., \& Gunawan, I. M. A. O. (2021). Pengembangan Sistem Informasi Agenda, Arsip Dan Persuratan Bappeda Kabupaten Badung. Majalah Ilmiah Universitas Tabanan, 18(1), 6370.

Vani, T., Hidayat, R., \& Yudhistira, A. Y. F. D. (2021). Rancang Bangun Mobile Commerce di Lamandau Store Berbasis Android berdasarkan User Centered Design (UCD). Jurnal Media Informatika Budidarma, 5(1), 287-296.

Yesputra, R., \& Marpaung, N. (2018). Penerapan Arsitektur Model View Contoller (Mvc) Pada Sistem Informasi E-Skripsi Stmik Royal. Jurnal INSTEK (Informatika Sains dan Teknologi), 3(2), 281290. 